\title{
The allergy gene: how a mutation in a skin protein revealed a link between eczema and asthma
}

\author{
W. H. Irwin McLean
}

Address: Department of Medicine, College of Life Sciences, University of Dundee, Dundee, DD1 5EH, UK

Email: w.h.i.mclean@dundee.ac.uk

FI000 Medicine Reports 201 I, 3:2 (doi:10.3410/M3-2)

This is an open-access article distributed under the terms of the Creative Commons Attribution-Non Commercial License (http://creativecommons.org/licenses/by-nc/3.0/legalcode), which permits unrestricted use, distribution, and reproduction in any medium, provided the original work is properly cited. You may not use this work for commercial purposes.

The electronic version of this article is the complete one and can be found at: http://f 1000 .com/reports/m/3/2

\begin{abstract}
Ichthyosis vulgaris is a common genetic skin disorder characterized by dry, scaly skin. About $1 \%$ of the European population have the full presentation of ichthyosis vulgaris; up to $10 \%$ have a milder, subclinical form. Atopic eczema is the most common, inflammatory skin condition, affecting $20 \%$ of children. It is often accompanied by a number of other allergies, including atopic asthma. Atopic eczema is a complex trait, where predisposing genes in combination with environmental stimuli produce the disease. Recently, we reported the first loss-of-function genetic mutations in the filaggrin gene as the cause of ichthyosis vulgaris. We noted people with ichthyosis vulgaris also have atopic eczema (and vice versa) and that the filaggrin gene sits in a known atopic eczema susceptibility locus. We went on to confirm that filaggrin mutations, carried by up to $10 \%$ of the population, are the major genetic predisposing factor for atopic eczema and the various allergies associated with atopic eczema. Filaggrin is a highly abundant protein expressed in the uppermost part of the epidermis that is critical to the formation and hydration of the stratum corneum-the outermost dead cell layers responsible for the barrier function of the skin. Filaggrin deficiency leads to a "leaky" skin barrier that allows higher than normal water loss (explaining the dry, scaly skin), as well as allowing entry of allergens through the epidermis where they trigger inflammatory and allergic immune responses (atopic eczema and allergies). This work has placed the skin barrier at the center stage of eczema and allergy research and has kick-started new therapy development programs aimed at repairing or enhancing skin-barrier function as a means of treating or preventing these very common diseases.
\end{abstract}

It was a tense Friday afternoon in October 2005. Four of us in the lab had been working furiously that week in the fear that our results would be scooped at any moment. (It was an unfounded worry, but we had no way of knowing that at the time.) We had recently found the first mutation in a gene associated with a relatively common skin disease, but our results didn't fully make sense, and we suspected there must be a second mutation hidden in this gene. A second mutation might explain the strange genetic patterns we had seen in affected families, and it also seemed to hint at a much bigger story.

A few months previously, we had started sequencing the gene encoding filaggrin-a gigantic protein expressed in large quantities in the outermost layers of the epidermis. The sequence of the filaggrin gene (FLG) was one of the last to be completed by the Human Genome Project, and for good reason-it is an unusually large and repetitive gene, making sequence analysis very difficult. To sequence it once was an effort that took years; to do it repeatedly, as we would have to for our mutational screens, was much more challenging. After months of perseverance and perspiration, Frances Smith, a senior research fellow in the lab, had managed to design a method to sequence one part of the gene. This allowed us to identify a single nonsense mutation in some of our patients with ichthyosis vulgaris, a hereditary disorder characterized by severe flaking of the skin. 
What made our discovery all the more satisfying was that others had been trying to sequence this gene for years. Beverly Dale and colleagues at the University of Washington in Seattle had identified the filaggrin protein in the 1980s and had sought its sequence, but there was a lot of contradictory information regarding its role in ichthyosis vulgaris. Three major laboratories had thrown their weight behind the sequencing effort, but with no success.

Part of the reason for the difficulty was that filaggrin is made in the form of a monster precursor protein called profilaggrin, which has a molecular weight of more than $400,000 \mathrm{Da}$ - eight to nine times more massive than most proteins. That in itself wasn't the problem from the standpoint of genetic analysis, but the structure of the gene is also unusual. The mRNA is huge, about 13,000 bases, almost all of which are encoded by a single exon. Unruly as the gene was, the real challenge was that the protein is a polymer made of 10 or more identical subunits with the same protein sequence. Therefore, within that big exon there are one-kilobase blocks of sequence that are roughly identical, arranged in a line, one after the other. That's where the real problem lay. When researchers tried to replicate a particular segment of the gene using a PCR (polymerase chain reaction) technique, the primers that mark the start and end of the DNA sequence were not specific enough to distinguish one segment of the polymeric gene from another. So when researchers tried to sequence the gene and look for mutations, it was never clear whether they were sequencing a unique region of the gene, or one of the other nine regions simultaneously. It was as if nature was having a joke at our expense.

My lab started to sequence FLG, the filaggrin gene, in American, Scottish, and Irish families suffering from ichthyosis vulgaris. Frances Smith and I had learned a few sequencing tricks from cloning another large, repetitive gene back in the mid-1990s, so when we started working on filaggrin, we found the first mutation fairly quickly, right at the start of this massive gene. Just as the literature had predicted, this mutation, which completely stops filaggrin protein production, was present in some, but not all, samples from patients with ichthyosis vulgaris. But strangely enough, when we looked at our "normal" controls, which should have lacked the mutation, about $4-5 \%$ also carried the defective gene. When my clinical collaborator, Alan Irvine from Our Lady's Children's Hospital in Ireland, took a closer look at patient records, he started to see a pattern. Patients with ichthyosis seemed to suffer from either a severe form or a mild form of the disease. In fact, about one in ten of the normal population also had ichthyosis, only it was such a mild, subclinical version of the condition that it could be treated with skin moisturizer to relieve the symptoms.

That's when we started searching in earnest for a second mutation. We figured that patients with a mutation on one allele of the gene would still have a second good copy of the gene on their other allele, producing filaggrin, just less of it, and explaining the mild form of the disease. A second mutation would knock out both copies of the gene, explaining the more severe cases. We had generated a large 12,000-base-pair PCR fragment containing one copy of the mutation from an American patient with severe ichthyosis, and we assumed the patient's other allele would carry a second mutation. We cloned the PCR fragments, and sequenced a clone lacking the first mutation. We didn't have primers that would sequence it fully, so we simply threw a whole bunch of sequencing primers at this clone, and as luck would have it, one of them landed near the second mutation. On that fateful Friday afternoon, we saw the first hint of the second mutation. By Saturday afternoon, after an overnight experiment, we had already validated it [1].

That may have been enough to start celebrating, but there was more riding on the finding than just this one rare disease. When Alan went back over his patient records, he noticed that ichthyosis vulgaris sufferers also exhibited another, very common, skin disease-eczema-much more frequently than the general population. I pulled together everyone in the lab on Monday, holding a sort of emergency meeting of the war cabinet, to discuss the possibility that we had not just one but two really huge stories. "Whatever you're doing," I told them, "put it to bed-everyone works on this for the next couple of months." It was a once-in-a-lifetime opportunity.

There was a chance that this enormous, bizarre skin protein not only was responsible for flaky skin, but could offer a new genetic and cellular explanation for eczema [2], as well as for other common allergies.

\section{The hunt}

I had thought about filaggrin for years. As a postdoc in Birgit Lane's lab in Dundee back in 1995, I had worked on a similarly large and clunky skin protein called plectin. The protein contained six repeated regions, each of which had additional small internal repeats. This fractal-like gene, with a large 7000-base-pair exon, was unlike anything I'd ever tried to clone. It was the great white whale of my postdoctoral work. We'd come into the lab every few days with a new idea for how to get at it, building a sizable toolbox of techniques and tricks that we used to finally elucidate the plectin gene's sequence. 


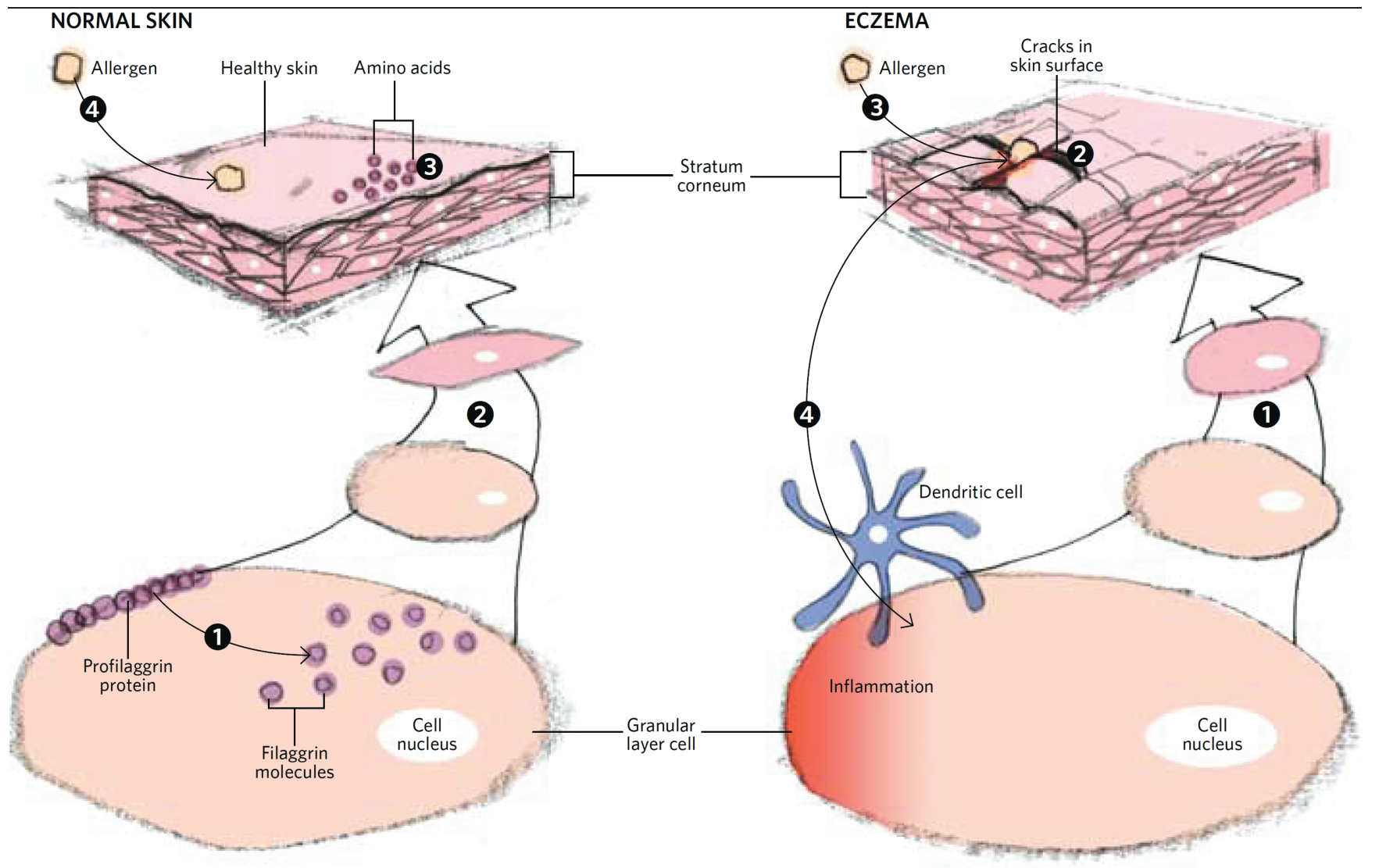

Normal skin (left): In the granular layer of normal skin, the large profilaggrin protein is dephosphorylated and enzymatically cut into I0-12 smaller filaggrin molecules (I). As these cells move up to form the stratum corneum, they flatten their shape by collapsing their keratin structure-a process aided by interaction with filaggrin proteins (2). In the stratum corneum, filaggrin degrades into amino acids essential for maintaining moisture in the outer layers of skin (3). The intact skin barrier of healthy skin keeps allergens, pathogens (bacteria and viruses) and chemical irritants out of the body (4).

Eczema (right): Mutations in the filaggrin gene greatly reduce the amount of filaggrin protein in the skin or lead to its complete absence (I), resulting in cracks in the skin barrier (2) that expose the lower layers to allergens which are usually kept out, thus causing eczema (3). Once foreign material, such as an allergen, passes through the defective skin barrier, it is spotted by cells of the immune system, leading to inflammation of the skin and other allergic responses (4). If a child is exposed to allergens through the skin, that exposure is more likely to prime the immune system to react aggressively to that allergen later in life, explaining the coincidence of asthma and eczema seen in patients throughout the world.

My interest in plectin started during my early postdoctoral work, which involved genetic disorders of keratin genes. Keratins form the filamentous cytoskeleton within epithelial cells of the epidermis. The stacked sheets of cells forming the skin's outermost layer function as a protective barrier between the organism and its environment. Epithelial cells gain their mechanical strength from this tough keratin cytoskeleton in their cytoplasm, and defects in keratin genes make the skin more fragile. In the case of the epidermal keratins, this manifests as skin blistering in response to trauma as mild as rubbing, often accompanied by overgrowth and thickening of the skin, as the epidermis tries in vain to compensate for the fragility of the cells. Some 23 of the 54 keratin genes are known to be linked to various human genetic diseases.
After working on keratin genes for a number of years, we went on to characterize and sequence genes encoding proteins such as plectin that either bind to keratins and anchor the cytoskeleton to membranes, or that modify the keratins, giving epithelial cells a plethora of properties, from elasticity to hardness and water resistance. One of these proteins, filaggrin, was similar in complexity to plectin. Given the strong hints that it might be involved in ichthyosis vulgaris, by the mid-1990s I was just itching to try to sequence its gene and look for disease-causing mutations. But the gene was off limits. I considered Beverly Dale and colleagues at Seattle (who had initially identified the protein) friendly rivals, and I knew that her lab was working out $F L G$ 's sequence. We liked those guys a lot. It was their gene, so we decided not to pursue it. 
Then, in 2004, at a meeting in Utah, Frances Smith and I met one of Beverly's colleagues, dermatologist Phil Fleckman. On the bus ride back from a social gathering near Park City, we started chatting about filaggrin. In the intervening years, a number of labs had had a go at sequencing filaggrin, but all had given up. Maybe it was finally our turn to try it. Phil sent us their DNA samples, and a few months later we had the first mutation, with the second mutation close on its tail.

When looking at the patient records for different varieties of ichthyosis vulgaris, Alan noticed that the patients had frequently also been diagnosed with atopic eczema, the most common skin disease. Atopic (or allergic) eczema affects about one in five children in industrialized nations. It is an inflammatory skin condition, usually starting in infancy or early childhood, with symptoms of red, inflamed, and intensely itchy skin. Eczema is very often accompanied by a plethora of allergies, including food and pet allergies, asthma, and hay fever.

Immediately, we went to the literature and found a 2001 study by Bill Cookson and his colleagues, now at Imperial College London. They had shown that there was an eczema susceptibility locus on chromosome 1 . We scanned that locus in the human genome databaseit was a very large area-and the filaggrin gene was bangsmack in the middle of it!

We went back to our DNA sample collection from about 50 Irish ichthyosis vulgaris patients and 200 members of the general population. It was a really tiny sample size for a case-control study. Most such genetic epidemiological studies for complex traits would have cases and controls that numbered in the thousands, so we weren't too hopeful about seeing a statistically significant link to eczema. We counted the number of people with a filaggrin mutation in the eczema patient group and in the general population, and compared the results using a statistical test. If the mutations were significantly more common in patients with eczema compared to the control group, then we had found an eczema gene. A significant difference between the cases and controls is measured by a $p$ value of 0.05 or lower. In complex-trait genetics at that time, you considered yourself lucky if you had something like 0.001 . So we were totally blown away when the statistical result from our relatively small study came back as $10^{-17}$ ! This meant we had unbelievably strong evidence that the filaggrin gene was involved in eczema. From our more recent studies, we have shown that up to $50 \%$ of children with moderate to severe eczema carry one or two mutations in the filaggrin gene [3].
A neighboring lab in Dundee, headed by Colin Palmer, had an ongoing study of the genetics of asthma. We analyzed their samples of 600 school kids from Dundee, Scotland, all of whom had asthma, as well as 1000 random population controls, for the two filaggrin mutations. When we sorted the kids that had both eczema and asthma from those with just asthma, the population divided into two groups of almost exactly 300 children each. Kids with asthma alone showed no association with the filaggrin mutations, but children with both diseases again showed a powerful statistical association.

That one simple experiment showed that at the molecular level there are two types of asthma: an asthma driven by a skin-barrier deficiency or eczema mechanism, and an asthma driven by a different mechanism. We published our initial asthma findings along with the eczema work. It was an unreal month-long rollercoaster ride. Six months later we had figured out how to fully sequence the filaggrin gene, and discovered that there are a number of common mutations in the gene that arose thousands of years ago in early human populations, in addition to many rare mutations that have arisen more recently. Not only was there an association between the mutations in the gene and disease in people of European descent, we also found that there are specific combinations of rare and common mutations in other, nonwhite population groups-in Asia, for example-making filaggrin an important eczema/allergy gene worldwide $[4,5]$.

\section{The genetic basis of allergies}

What at first appeared to be a surprising association began to make sense on a cellular and molecular level as we continued to study the protein. Filaggrin is crucial for the formation of the stratum corneum, the layer of dead cells at the surface of the skin, and also for the hydration of this crucial barrier layer. People who have mutations in one or both copies of the filaggrin gene produce dry and flaky skin that is permeable to allergens or chemical irritants. When the barrier is broken, foreign material is able to pass through these skin layers. We think that childhood eczema-which usually first occurs within the first few months of life-is an indication that foreign pathogens and irritants have passed through an abnormally porous skin layer, activating a strong allergic immune response, and thus priming the body to react to antigens that it would not normally encounter by this route. Later in life, when the child's immune system comes into contact with those same allergens, perhaps through the lungs, it reacts aggressively, causing the inflammation in the lungs that results in shortness of breath. In fact, many children with eczema have multiple allergies to house dust, pet hair, and other substances. 
For the preceding 20 years or so, the study of eczema and asthma had been dominated by immunological theories. The predominant hypothesis dictated that these diseases were caused by some malfunction of the immune system. Indeed, patients who suffer from both eczema and asthma have an overactive $\mathrm{T}$ helper 2 (Th2) immune system, the arm of the adaptive immune response that spurs immunoglobulin E (IgE) antibody production against allergens. While Th2 cytokines are indeed present, we have shown that it's not a primary malfunction in the immune system, but a genetic malfunction in the skin that initiates eczema and, in some cases, asthma. Skin-barrier function is now center stage in eczema research. It should be noted, however, that filaggrin is not the only predisposing gene for eczema, and it is likely that others will emerge, some of which are likely to involve immune system malfunction.

Excited by these findings, we quizzed our colleagues for information about other diseases that might possibly be affected by filaggrin-gene mutations. The next natural target was psoriasis, another disease characterized by itchy, flaky, red patches of skin. We found no association with any filaggrin mutation, although it appears that a nearby gene is involved in psoriasis susceptibility.

\section{Curing a genetic allergy?}

The question now is how to prevent eczema, asthma, and allergies from occurring in patients with the susceptibility mutations in their filaggrin gene. If it were possible to find a cure for eczema in adults, could we also cure asthma, or would it be too late, with the immune system permanently primed against allergens? I would argue that it might at least help. If the skin barrier is not repaired, then the immune system will constantly produce more antibodies in response to allergens that continue to get past the barrier. Stopping that assault may have some beneficial effects. The alternate possibility is that we may need to prevent eczema in young children before they become sensitized. If the latter proves true, would it be sufficient to curb eczema early in life, as the immune system develops? These are all questions we are gearing up to answer.

We've recently published work on a mouse model with a mutation in the murine filaggrin gene that is highly analogous to the human mutations. These mice have many of the hallmarks of eczema, including elevated IgE and Th2 cytokine responses, thus providing compelling experimental evidence for the skin-barrier hypothesis.
The plan is to create a mouse model in which we can switch the filaggrin gene on or off at will as the mouse develops, to define the most efficacious period for intervention to prevent eczema.

We've also started to look for ways to help the body replace filaggrin at the cellular level. We are currently searching small-molecule chemical libraries for new classes of compounds that might induce skin cells to produce more filaggrin protein. Results look promising, and we are hopeful that in a few years' time, new drugs or creams that enhance skin-barrier function will be available to treat these common diseases.

\section{Abbreviations}

$\mathrm{Da}$, dalton; $F L G$, filaggrin gene; IgE, immunoglobulin E; PCR, polymerase chain reaction; Th2, T helper 2.

\section{Competing interests}

The author declares that he has no competing interests.

\section{Acknowledgements}

The author would like to thank the many patients and their families, without whose participation his research would not have been possible. Filaggrin research in the McLean laboratory is supported by grants from the British Skin Foundation, National Eczema Society, Medical Research Council (ref G0700314), the Wellcome Trust (refs 090066/B/09/Z and 092530/Z/10/Z) and donations from families affected by eczema in Scotland.

\section{References}

I. Smith FJ, Irvine AD, Terron-Kwiatkowski A, Sandilands A, Campbell LE, Zhao Y, Liao H, Evans AT, Goudie DR, Lewis-Jones S, Arseculeratne G, Munro CS, Sergeant A, O'Regan G, Bale SJ, Compton JG, DiGiovanna J], Presland RB, Fleckman P, McLean WH: Loss-of-function mutations in the gene encoding filaggrin cause ichthyosis vulgaris. Nat Genet 2006, 38:337-42.

2. Palmer CN, Irvine AD, Terron-Kwiatkowski A, Zhao Y, Liao H, Lee SP, Goudie DR, Sandilands A, Campbell LE, Smith FJ, O'Regan GM, Watson RM, Cecil JE, Bale SJ, Compton JG, DiGiovanna JJ, Fleckman P, Lewis-Jones S, Arseculeratne G, Sergeant A, Munro CS, El Houate B, McElreavey K, Halkjaer LB, Bisgaard H, Mukhopadhyay S, McLean WH: Common loss-of-function variants of the epidermal barrier protein filaggrin are a major predisposing factor for atopic dermatitis. Nat Genet 2006, 38:44I-6.

FI000 Factor 12

Evaluated by Marc Rothenberg 02 May 2006, Michele Ramsay 08 May 2006

3. Sandilands A, Terron-Kwiatkowski A, Hull PR, O'Regan GM, Clayton TH, Watson RM, Carrick T, Evans AT, Liao H, Zhao Y, Campbell LE, Schmuth M, Gruber R, Janecke AR, Elias PM, van Steensel MA, Nagtzaam I, van Geel M, Steijlen PM, Munro CS, Bradley DG, Palmer CN, Smith FJ, McLean WH, Irvine AD: Comprehensive analysis of the gene encoding filaggrin 
uncovers prevalent and rare mutations in ichthyosis vulgaris and atopic eczema. Nat Genet 2007, 39:650-54.

FI000 Factor 6

Evaluated by Bettina Wedi 06 Jun 2007

4. Fallon PG, Sasaki T, Sandilands A, Campbell LE, Saunders SP, Mangan NE, Callanan JJ, Kawasaki H, Shiohama A, Kubo A, Sundberg JP, Presland RB, Fleckman P, Shimizu N, Kudoh J, Irvine $A D$, Amagai $M$, McLean WH: A homozygous frameshift mutation in the mouse FLG gene facilitates enhanced percutaneous allergen priming. Nat Genet 2009, 4 I:602-8.

FI000 Factor 6

Evaluated by Eric Simpson 22 Feb 2010

5. Sandilands A, Sutherland C, Irvine AD, McLean WH: Filaggrin in the frontline: role in skin barrier function and disease. J Cell Sci 2009, I 22: I 285-94. 